\title{
Acute Effects of Electronic Cigarette Inhalation on the Vasculature and the Conducting Airways
}

\author{
Lukasz Antoniewicz $^{1}$ (D) Amelie Brynedal ${ }^{2} \cdot$ Linnea Hedman $^{3,4} \cdot$ Magnus Lundbäck $^{5}$. Jenny A. Bosson ${ }^{2}$
}

Published online: 8 April 2019

(C) The Author(s) 2019

\begin{abstract}
The use of electronic cigarettes has increased exponentially since its introduction onto the global market in 2006. However, short- and long-term health effects remain largely unknown due to the novelty of this product. The present study examines the acute effects of e-cigarette aerosol inhalation, with and without nicotine, on vascular and pulmonary function in healthy volunteers. Seventeen healthy subjects inhaled electronic cigarette aerosol with and without nicotine on two separate occasions in a double-blinded crossover fashion. Blood pressure, heart rate, and arterial stiffness measured by pulse wave velocity and pulse wave analysis were assessed at baseline, and then at $0 \mathrm{~h}, 2 \mathrm{~h}$, and $4 \mathrm{~h}$ following exposure. Dynamic spirometry and impulse oscillometry were measured following vascular assessments at these time points, as well as at $6 \mathrm{~h}$ following exposure. e-Cigarette aerosol with nicotine caused a significant increase in heart rate and arterial stiffness. Furthermore, e-cigarette aerosol-containing nicotine caused a sudden increase in flow resistance as measured by impulse oscillometry, indicating obstruction of the conducting airways. Both aerosols caused an increase in blood pressure. The present study indicates that inhaled e-cigarette aerosol with nicotine has an acute impact on vascular and pulmonary function. Thus, chronic usage may lead to long-term adverse health effects. Further investigation is warranted.
\end{abstract}

Keywords Electronic cigarettes $\cdot$ ENDS $\cdot$ Arterial stiffness $\cdot$ Pulse wave velocity $\cdot$ Augmentation index $\cdot$ IOS $\cdot$ e-Cig

\section{Introduction}

Handling Editor: Rajiv Janardhanan.

Electronic supplementary material The online version of this article (https://doi.org/10.1007/s12012-019-09516-x) contains supplementary material, which is available to authorized users.

Lukasz Antoniewicz

lukasz.antoniewicz@ki.se

1 Division of Internal Medicine, Department of Clinical Sciences, Karolinska Institutet, Danderyd University Hospital, 18288 Stockholm, Sweden

2 Department of Public Health and Clinical Medicine, Umeå University, Umeå, Sweden

3 Department of Public Health and Clinical Medicine, Occupational and Environmental Medicine, The OLIN Unit, Umeå University, Umeå, Sweden

4 Division of Nursing, Department of Health Science, Luleå University of Technology, Luleå, Sweden

5 Division of Cardiovascular Medicine, Department of Clinical Sciences, Karolinska Institutet, Danderyd University Hospital, Stockholm, Sweden
Tobacco smoke has long been associated with damage and disease in nearly every organ of the body, with the most common being various types of cancer as well as cardiovascular and respiratory disease [1]. Due to an increased public awareness of these adverse health effects in addition to stricter laws and regulations, the Western world has witnessed a steady decline in cigarette smoking over the last few decades [2]. On the other hand, the electronic cigarettes (e-cigarettes), introduced on the market in 2006, have gained heavily in popularity on a global scale [3].

All e-cigarette systems are comprised of a battery, a cartridge/tank with liquid (e-liquid), and an atomizer which contains a wick, coil, and heating element. The wick draws the e-liquid into the coil and when activated the e-liquid is heated, the aerosol is then inhaled by the e-cigarette user. The e-liquid is based on a mixture of vegetable glycerin and propylene glycol and may contain added flavorings and/ or varying amounts of nicotine [4]. Both are common food additives and also found in numerous industrial, commercial, and pharmaceutical products. Propylene glycol is a known 
eye and airway irritant and commonly used in fog machines [5]. However, it is important to note that it is still unclear whether either has negative health effects when heated and inhaled.

To date, there are a handful of human experimental studies examining the health effects of e-cigarette usage. Two studies have demonstrated lower amounts of urinary biomarkers for oxidative stress and carcinogens in chronic e-cigarette users compared to smokers [6, 7]. Another study showed impaired flow mediated dilation and an increase in serum biomarkers for oxidative stress following exposure to electronic cigarette aerosol (ECA) with nicotine [8]. Our group has recently demonstrated that ten puffs of ECA with nicotine mobilized endothelial progenitor cells in healthy volunteers [9]. We speculated that this was due to endothelial activation or damage. However, none of these studies could differentiate if the observed effects were due to the nicotine content or other contributing factors found in the ECA. Moheimani et al. observed an increase in cardiac sympathetic nerve activity in healthy volunteers exposed to ECA with nicotine but not following ECA without nicotine or sham smoking [10]. Two further studies found that inhalation of ECA with nicotine but not without nicotine caused an increased arterial stiffness at 5-10 min following inhalation, a known independent risk factor for both myocardial infarction and stroke [11-13].

Vardavas et al. demonstrated that exposure to ECA increased airway obstruction measured by impulse oscillometry (IOS), but not by conventional spirometry [14]. IOS is commonly used clinically in the pediatric population to assess obstructive pulmonary diseases. This method is highly reproducible and it allows a deeper understanding of small airway diseases and may even diagnose preclinical obstructive states [15]. Another study showed that passive ECA exposure increased fractional exhaled nitric oxide (FeNO), an airway inflammation marker commonly assessed in asthmatics [16]. However, other studies have pointed towards a decrease in FeNO upon ECA inhalation $[14,17]$.

To further understand acute vascular and pulmonary effects of ECA and nicotine, we performed a study in which healthy volunteers were exposed to active e-cigarette inhalation with or without nicotine.

\section{Methods}

\section{Study Design and Subjects}

Employing a randomized, double-blinded, crossover design, 17 healthy occasional users of tobacco products (max ten cigarettes/month), inhaled 30 puffs of ECA with or without nicotine during a 30-min period on two separate occasions.
The wash out period was a minimum of 1 week. Prior to the study days, volunteers had to abstain from alcohol and caffeine for $12 \mathrm{~h}$, from heavy exercise for $24 \mathrm{~h}$ and from other tobacco and nicotine-containing products for 14 days. All subjects underwent a preliminary clinical examination including ECG, dynamic spirometry, pregnancy test, and routine blood tests including full blood count, electrolytes, creatinine, apolipoproteins, HbA1c, aPTT, and PT. Exclusion criteria included any form of cardiovascular, respiratory, systemic or chronic disease, symptoms of infection or inflammation within 2 weeks prior to study start, BMI $\geq 30$ or pregnancy.

\section{e-Cigarette Exposure}

The e-liquid base consisted primarily of $49.4 \%$ propylene glycol, $44.4 \%$ vegetable glycerin, and 5\% ethanol without any added flavorings (Valeo laboratories $\mathrm{GmbH}$, Germany). Premixed e-liquids with and without added nicotine were used $(19 \mathrm{mg} / \mathrm{ml}$ and $0 \mathrm{mg} / \mathrm{ml}$ resp.). A variable mod thirdgeneration e-cigarette was used (eVic-VT, Shenzhen Joyetech Co., Ltd., China). The same settings were used for all exposures (temperature $230{ }^{\circ} \mathrm{C}$, effect $32 \mathrm{~W}$, resistance 0.20 $\Omega$ ). A dual coil nickel atomizer was used. All exposures were performed in a well-ventilated, temperature-controlled room. Volunteers inhaled 30 puffs from the e-cigarette for $30 \mathrm{~min}$, with each puff lasting approximately three seconds.

\section{Measurements}

Vascular measurements included heart rate (HR), systolic and diastolic blood pressure (SBP, DBP), and arterial stiffness. Pulmonary measurements consisted of dynamic spirometry, impulse oscillometry (IOS), and fractional exhaled nitric oxide (FeNO). Vascular measurements were performed at baseline and then every $10 \mathrm{~min}$ for $30 \mathrm{~min}$ following the inhalations at $0 \mathrm{~h}$ (directly following exposure), $2 \mathrm{~h}$, and $4 \mathrm{~h}$ (Fig. 1). Pulmonary measurements were carried out following vascular measurements as well as at 6-h post-exposure.

Using a double-blinded, crossover study design, volunteers were randomized to e-cigarette inhalation either with or without nicotine as their first exposure. Vascular measurements included systolic and diastolic blood pressure, heart rate, and arterial stiffness and were measured at baseline and following exposure, immediately $(0 \mathrm{~h}), 2 \mathrm{~h}$, and $4 \mathrm{~h}$ afterwards. These measurements were performed in 10-min intervals over $30 \mathrm{~min}$. Respiratory measurements included dynamic spirometry, impulse oscillometry (IOS), and fractional exhaled nitric oxide (FeNO) and were performed directly following the vascular measurements and additionally at 6 -h post-exposure. 
Fig. 1 Study design

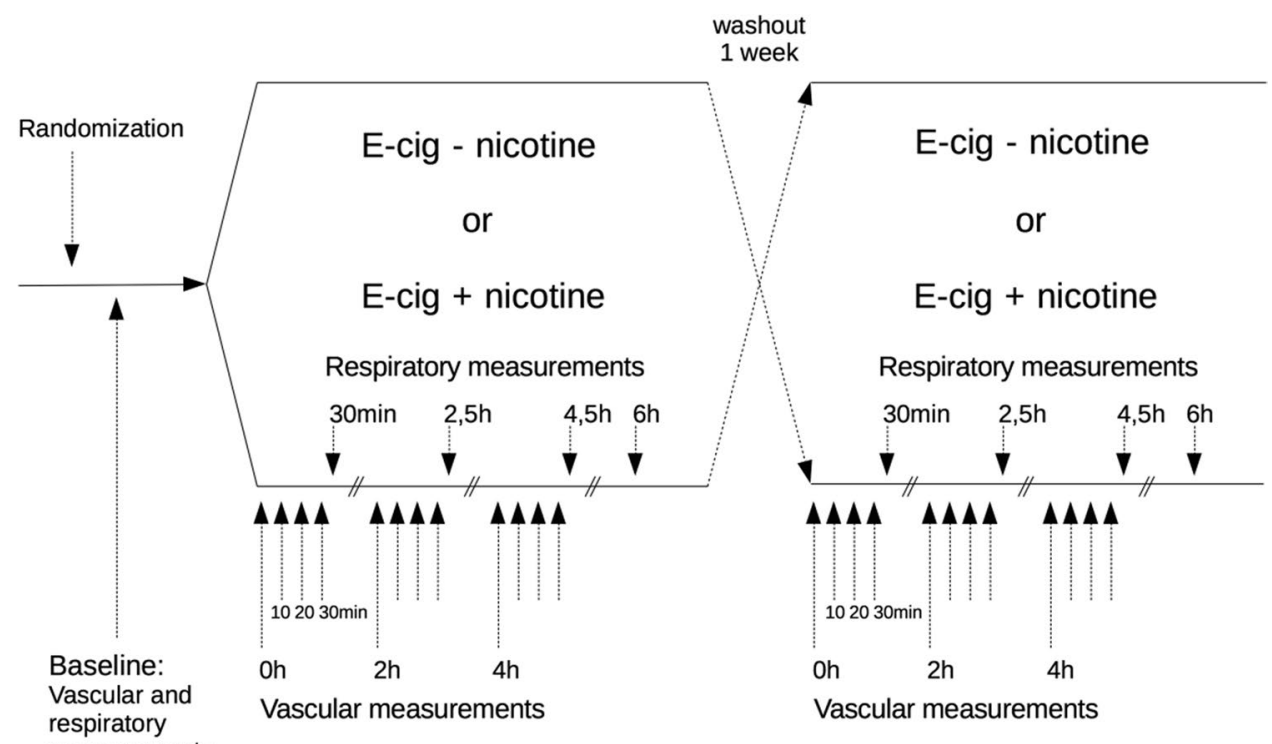

\section{Vascular Measurements}

All assessments were performed in a quiet, temperaturecontrolled room by one investigator with volunteers in a semi-supine position. Blood pressure and heart rate were measured using a validated semi-automatic oscillometric sphygmomanometer (Omron M7, Omron Healthcare Europe B. V., Hoofddorp, NL).

Arterial stiffness was assessed using pulse wave analysis and pulse wave velocity (PWV). PWV was determined by the Vicorder ${ }^{\mathrm{TM}}$ system (Skidmore Medical, Bristol, UK). This system measures the pulse transit time between two inflatable cuffs; one placed around the neck and the other around the thigh in order to register the pulse waves in the carotid and femoral arteries. Pulse wave analysis was assessed by micromanometer applanation tonometry (Millar Instruments, Texas, USA) on the right radial artery and analyzed with SphygmoCor ${ }^{\mathrm{TM}}$ software (AtCor Medical, Sydney, Australia), which then evaluates the aortic pulse pressure waveform via a validated mathematical transfer function. This waveform comprises a forward pressure wave, originating from the ventricular contraction of the heart and a reflected wave caused by the peripheral vascular resistance. Augmentation index and augmentation pressure were calculated from this waveform. Since augmentation index is inversely proportional to $\mathrm{HR}$ it was normalized for a HR at $75 \mathrm{bpm}$ (AIx 75). All measurements complied within the SphygmoCor ${ }^{\mathrm{TM}}$ quality control criteria [18].

\section{Respiratory Measurements}

All respiratory measurements were performed with volunteers sitting in an upright position using a standard nose clip.
FeNO was assessed with the Niox Mino system (Aerocrine AB, Solna, Sweden) in accordance with instructions from the manufacturer. Dynamic spirometry was assessed using a Jaeger Masterscope spirometer (Beckton Dickinson and Co., New Jersey, US), following European Respiratory Society (ERS) and American Thoracic Society (ATS) guidelines [19]. Three consecutive measurements of technically acceptable quality were collected and the highest value reported.

IOS was evaluated with a tremoFlo ${ }^{\mathrm{TM}}$ device (Thorasys Inc., Montreal, Canada). All measurements were performed according to the manufacturer's guidelines and following ERS standards [15]. Pulmonary resistance $(\mathrm{R})$ and reactance $(\mathrm{X})$ were measured at oscillation frequencies from 5 to $37 \mathrm{~Hz}$. Low frequencies $(5 \mathrm{~Hz})$ penetrate deep into the lung periphery, whereas mid-frequencies $(19 \mathrm{~Hz})$ merely reach the upper airways. Hence, resistance at $5 \mathrm{~Hz}(\mathrm{R} 5 \mathrm{~Hz})$ reflects the whole respiratory system, whereas resistance at higher frequencies (R19 Hz) reflect the upper airways. Furthermore, the difference between low and high frequencies is used to specify the resistance in the peripheral airways $(\mathrm{R} 5-19 \mathrm{~Hz})$. Reactance at $5 \mathrm{~Hz}(\mathrm{X} 5 \mathrm{~Hz})$ illustrates the elastic properties of the lung and obstruction of the smaller airways. Resonant frequency (fres) is referred to as the point where reactance is zero and the area under the curve from $X 5 \mathrm{~Hz}$ to fres is referred to as the area of reactance (AX). Three measurements with good technical quality were reported as mean values.

\section{Cotinine Analysis}

Serum cotinine levels at baseline were measured using a commercially available ELISA method (Calbiotech, 
Spring valley, CA, US) in accordance with the manufacturer's instructions.

\section{Statistical Analysis}

The statistical analyses were performed with SPSS 24.0 (IBM Corporation, NY, US) and GraphPad Prism 7.0 (GraphPad Software Inc., CA, US). Prior to analysis, data were checked for normality both visually and by Shapiro-Wilk test. Skewed variables (FeNO, R5-19, AX, fres) were checked for outliers and one subject had to be removed from FeNO analysis due to overall high values during both exposures. Skewed variables were analyzed following logarithmic transformation and two-way repeated measures ANOVA was performed. If Mauchly's test for sphericity was violated, Greenhouse-Geisser corrected results were presented. Within-subject contrasts were analyzed to compare baseline values to all other time points. $P$-values of $<0.05$ were considered statistically significant. Statistical analyses were performed by blinded investigators.

Power analysis calculations based on our previous particulate matter exposure study results, which also employed these methods, determined a sample size of $n=15$ [20].

The study was approved by the local Ethics Review Board in Umeå. The study was performed in accordance to the Declaration of Helsinki and with the written informed consent of all participants.

\section{Results}

Two subjects were excluded due to elevated cotinine values at baseline, indicating non-compliance with the study protocol. Fifteen subjects (nine females, six males, mean age $26 \pm 3$ years), all healthy, sporadic smokers, were included into the analysis. Routine blood samples as well as BMI and waist circumference were taken prior to the study. Mean values of the subject characteristics are shown in Online Resource 1.

\section{Vascular Measurements}

All vascular measurements are shown in Table 1. Following both exposures (with and without nicotine), there was a significant increase in SBP and DBP that remained elevated for 10 and $30 \mathrm{~min}$, respectively (Fig. 2, Table 1). HR, PWV, and AIx75 increased significantly following exposure to ECA with nicotine and remained elevated for $20 \mathrm{~min}$ as compared to ECA without nicotine (Figs. 2, 3, Table 1).

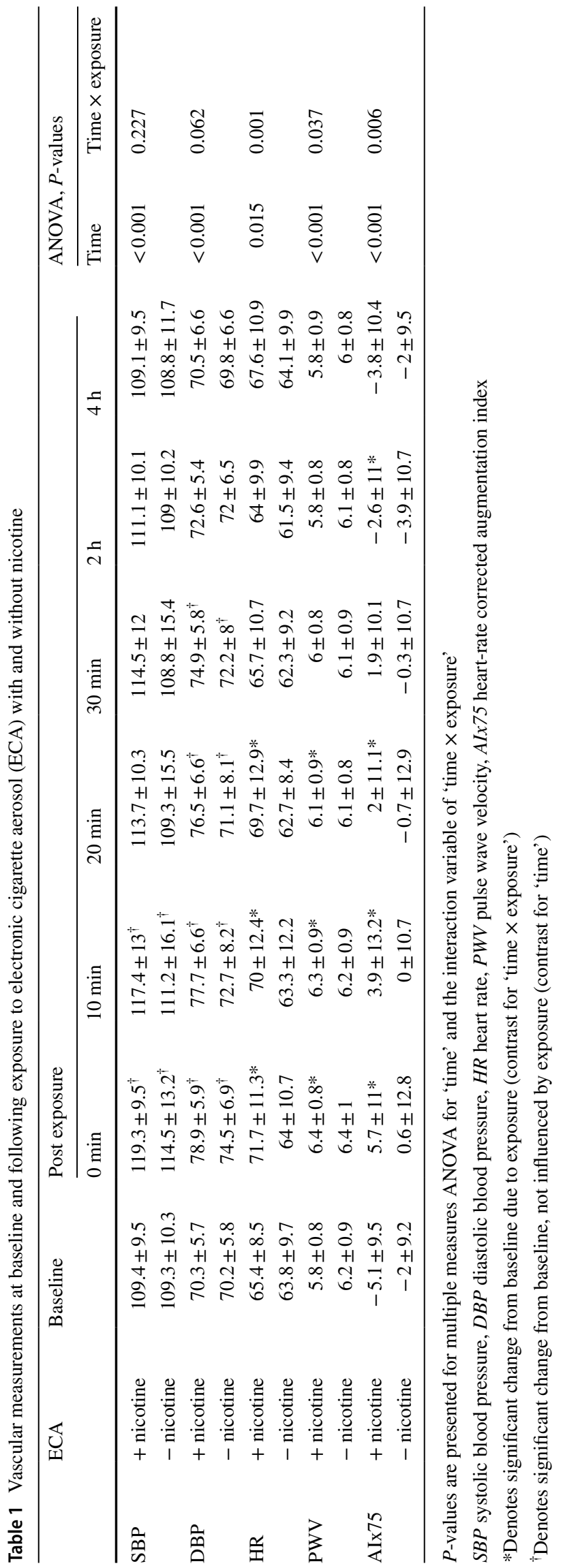




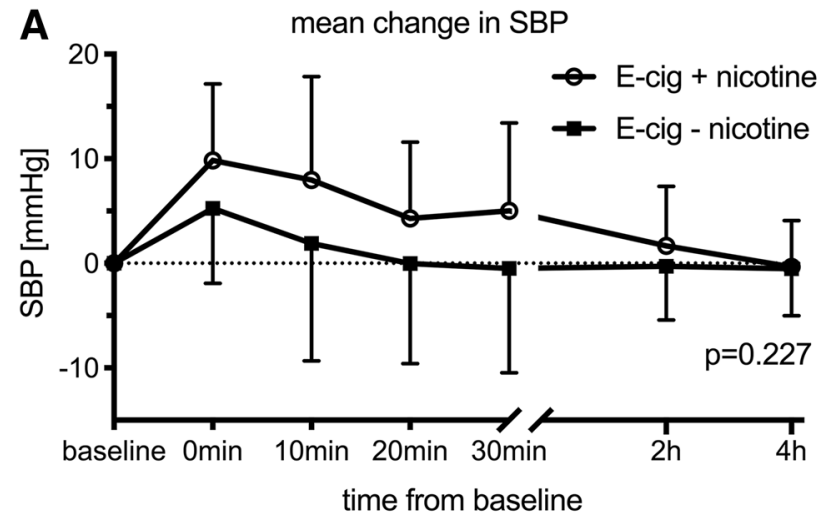

B mean change in DBP
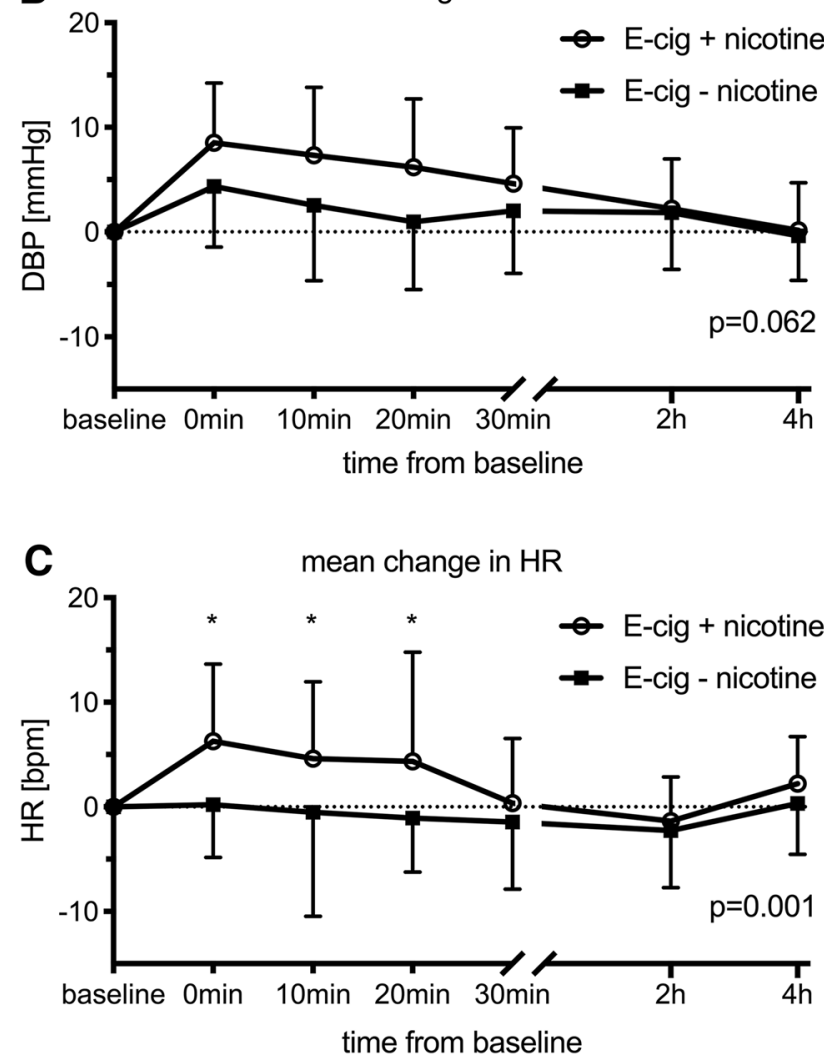

Fig. 2 Effects on blood pressure and heart rate. Mean change in vascular measurements with standard deviations from baseline following exposure to e-cigarette aerosol with and without nicotine. a systolic and $\mathbf{b}$ diastolic blood pressure (SBP, DBP), $\mathbf{c}$ heart rate (HR). $P$-values are presented for multiple measures ANOVA for the interaction variable of 'time $\times$ exposure.' *Denotes significant change from baseline due to exposure (contrast for 'time $\times$ exposure')

\section{Respiratory Measurements}

Results from respiratory measurements are presented in Table 2. Thirty minutes following exposure to ECA with nicotine, flow resistance at $5,11,13,17$, and $19 \mathrm{~Hz}$ was significantly increased (Fig. 4, Table 2). Resonance frequency
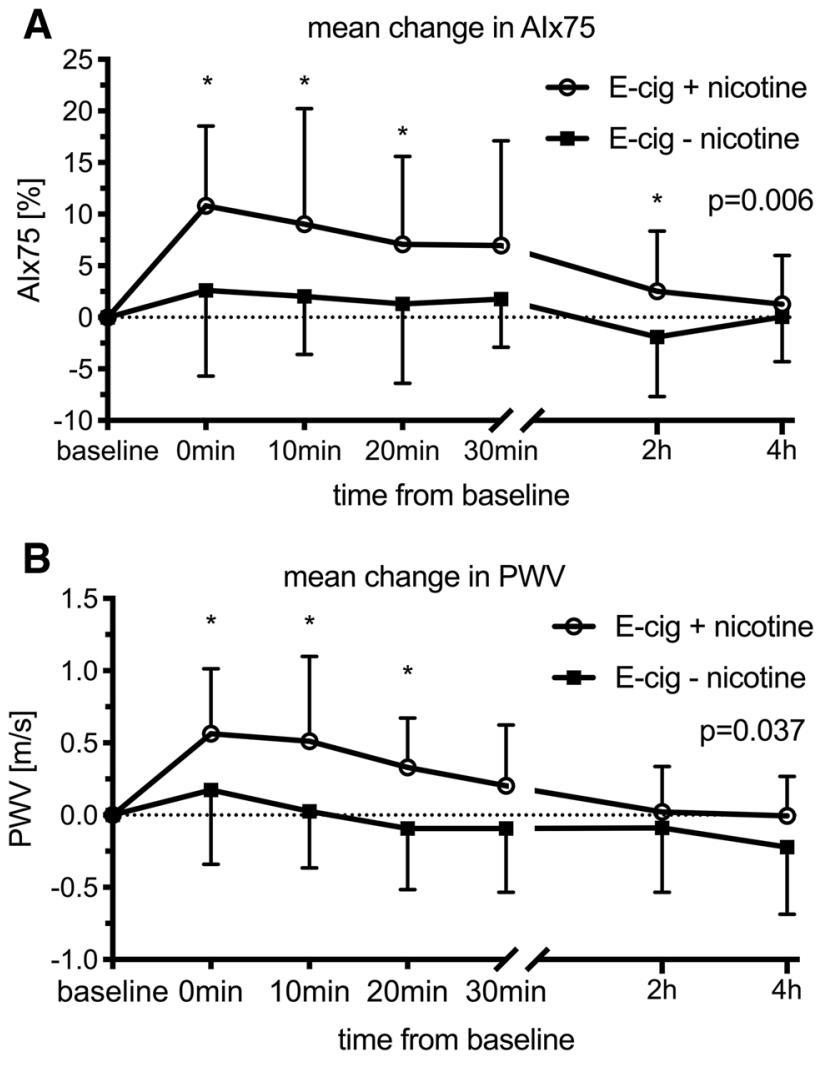

Fig. 3 Effects on arterial stiffness. Mean change in arterial stiffness with standard deviations from baseline following exposure to e-cigarette aerosol with and without nicotine. a heart-rate corrected augmentation index (AIx75) and b pulse wave velocity (PWV). $P$-values are presented for multiple measures ANOVA for the interaction variable of 'time $\times$ exposure.' *Denotes significant change from baseline due to exposure (contrast for 'time $\times$ exposure')

(fres) decreased at $6 \mathrm{~h}$ following inhalation of ECA without nicotine. Flow reactance at $5 \mathrm{~Hz}(\mathrm{X} 5 \mathrm{~Hz})$, the difference of R5 Hz and $\mathrm{R} 19 \mathrm{~Hz}(\mathrm{R} 5-19 \mathrm{~Hz})$, and reactance area (AX) remained unaffected following both inhalation exposures (Fig. 4, Table 2).

FeNO increased significantly at $2 \mathrm{~h}$ after both exposures (ECA with and without nicotine). Vital capacity (VC) decreased following exposure to ECA with and without nicotine and remained decreased after $2 \mathrm{~h} . \mathrm{FEV}_{1}$ did not change significantly over time.

\section{Discussion}

To the best of our knowledge, this is the first comprehensive study in human volunteers that examines acute vascular as well as respiratory effects of electronic cigarette aerosol (ECA) inhalation, both with and without nicotine.

This study shows an acute increase in arterial stiffness, both in terms of PWV and AIx75, following exposure to 
Table 2 Respiratory measurements at baseline and following exposure to electronic cigarette aerosol (ECA) with and without nicotine

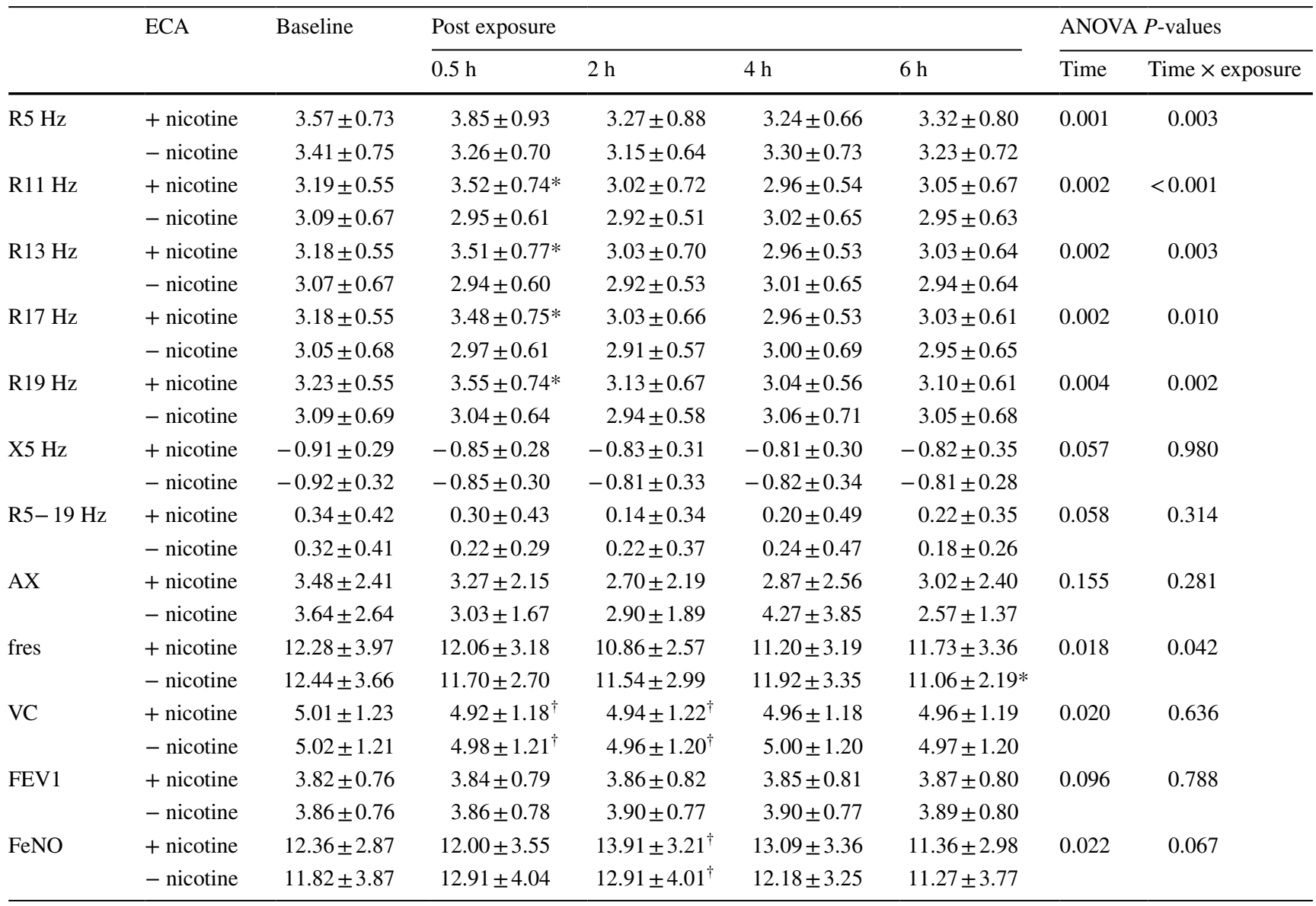

Impulse oscillometry: Flow resistance at 5, 11, 13, 17, and $19 \mathrm{~Hz}(\mathrm{R} 5 \mathrm{~Hz}, \mathrm{R} 11 \mathrm{~Hz}, \mathrm{R} 13 \mathrm{~Hz}, \mathrm{R} 17 \mathrm{~Hz}, \mathrm{R} 19 \mathrm{~Hz})$, reactance at $5 \mathrm{~Hz}$ (X5 Hz), the difference of R5 Hz and R19 Hz (R5-19 Hz), reactance area (AX) and resonance frequency (fres). Dynamic spirometry: Vital capacity (VC) and forced expiratory volume in one second $\left(\mathrm{FEV}_{1}\right)$. Fractional exhaled nitric oxide $(\mathrm{FeNO}) . P$-values are presented for multiple measures ANOVA for 'time' and the interaction variable of 'time $\times$ exposure'

*Denotes significant change from baseline due to exposure (contrast for 'time $\times$ exposure')

†Denotes significant change from baseline, not influenced by exposure (contrast for 'time')

ECA with nicotine, with a return to baseline values 30-min post-exposure. Increased arterial stiffness is a blood pressure-independent risk factor for cardiovascular events such as myocardial infarctions and stroke [21]. Recently, two other studies demonstrated that a short exposure to ECA with nicotine caused increased arterial stiffness directly following exposure, however, the duration of this change was not assessed in these studies [11, 12]. Applying a Mobil-OGraph, one pilot study indicated that the increase in arterial stiffness following ECA with nicotine occurs during the first 20 min following exposure and then returns to baseline values afterwards [22]. The present study confirms these findings with two well-established methods for the measurement of arterial stiffness.

There is an ongoing debate on which role nicotine plays in the pathophysiology of atherosclerosis and whether if, and how it may accelerate vascular disease [23]. There are many pathways through which nicotine may cause negative effects on the cardiovascular system. Nicotine has been demonstrated to elicit strong sympathomimetic effects, diminish coronary blood flow, impair endothelial function, enhance inflammation and arteriogenesis, as well as cause insulin resistance [23]. Epidemiological data that correspond with these findings are sparse, as most people tend to use tobacco products as opposed to products containing solely nicotine. Investigating oral snus usage may to some extent reflect long-term nicotine effects, as this product contains high amounts of nicotine and smaller amounts of known health hazardous compounds associated with combustible tobacco [24]. Snus use has been demonstrated to be associated with increased mortality following myocardial infarctions and stroke as well as increased risk of type II diabetes [25-28]. However, transdermal nicotine replacement therapy seems to be safe in patients with cardiovascular disease [29]. It is 

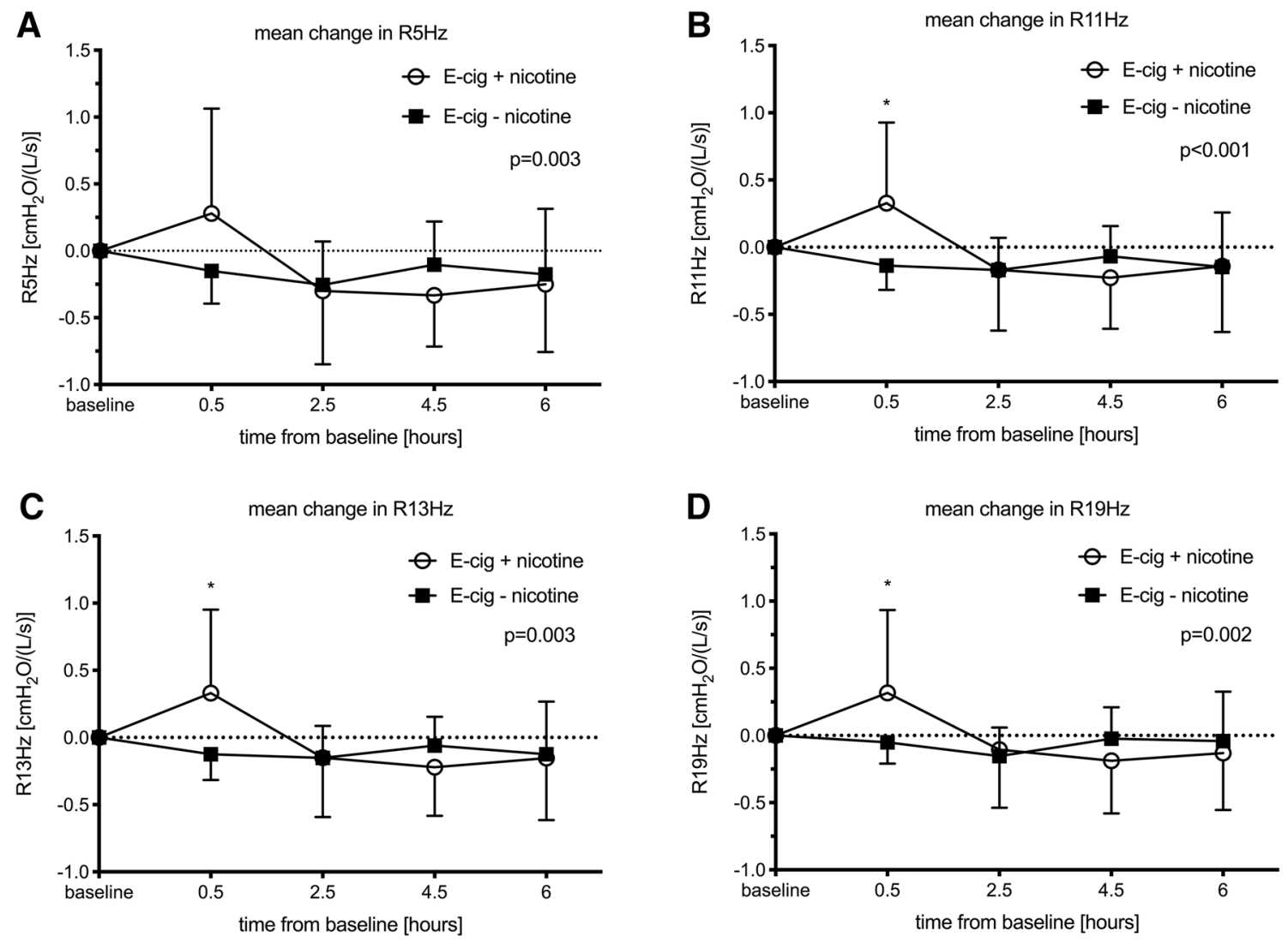

Fig. 4 Effects on airways measured by impulse oscillometry (IOS). Mean change and standard deviations from baseline in flow resistance at 5, 11, 13, and $19 \mathrm{~Hz}(\mathrm{R} 5 \mathrm{~Hz}, \mathrm{R} 11 \mathrm{~Hz}, \mathrm{R} 13 \mathrm{~Hz}, \mathrm{R} 19 \mathrm{~Hz}) . P$-values

not unlikely that the pathophysiological effect of nicotine is determined by pharmacokinetics; nicotine administered in tablet form does not give the very quick and high rise in blood nicotine levels as seen following cigarette smoking, inhalation of ECA, or oral snus use [30-32].

In the current study, impulse oscillometry exhibited conducting airway obstruction directly following exposure to ECA-containing nicotine. In 2013, Vardavas et al. demonstrated that a short exposure to ECA caused a rapid increase in airway obstruction [14]. Our study shows a similar impact on the conducting airways, yet only following inhalation of nicotine-containing ECA. These results correspond with findings that inhaled nicotine alone has airway obstructing features in a dose-dependent manner [33]. Itsaso GarciaArcos et al. demonstrated that mice exposed to ECA-containing nicotine displayed an increased cytokine expression as well as airway hyperreactivity, in addition to lung tissue destruction normally associated with COPD [34]. This indicates that inhaled nicotine may have additional adverse pulmonary effects compared to the already known systemic effects when administered orally.

It is well known that smoking cessation leads to dramatically improved lung function and reduced airway

are presented for multiple measures ANOVA for the interaction variable of 'time $\times$ exposure.' *Denotes significant change from baseline due to exposure (contrast for 'time $\times$ exposure')

inflammation, notably so in asthmatic patients. This was demonstrated by Chaudhuri and colleagues, who studied asthmatic patients that quit smoking compared to asthmatic patients who continued to smoke conventional cigarettes [35]. After only 6 weeks of smoking cessation, FEV $_{1}$ had increased with $407 \mathrm{ml}$ compared to those who continued smoking. In a small retrospective study, Polosa et al. investigated asthmatic patients who quit smoking conventional cigarettes and switched to e-cigarette use and demonstrated a comparatively smaller increase in $\mathrm{FEV}_{1}$ of around $100 \mathrm{ml}$ following a full 12 months of e-cigarette use [36]. Furthermore, a recently published epidemiological study highlighted e-cigarette use as a risk factor for asthma as well as more severe asthmatic episodes among high school students [37]. These findings, combined with our novel data that added nicotine in ECA likewise causes airway obstruction, point towards e-cigarettes as a poor choice for aiding in smoking cessation, particularly for individuals with bronchial hyperreactivity.

We observed a small yet significant decrease in vital capacity (VC) and a marginal significant increase in FeNO following both exposures. Schober et al. showed a similar increase in FeNO consequent to second-hand e-cigarette 
exposure, whereas other studies have reported no effect or even reduced levels of FeNO after e-cigarette usage $[14,16,17]$. Changes in VC have not been observed in any other previous studies $[14,17]$. These observations are difficult to fully interpret as the changes were minor and lie within repeatability range. Therefore, further studies are needed to clarify whether these findings have any significant clinical impacts following short- or long-term e-cigarette usage [19].

\section{Study Limitations}

IOS, spirometry, and FeNO measurements did not start directly following ECA inhalation. They were performed after the vascular assessments, i.e., $30 \mathrm{~min}$ after exposure. Our study protocol is based on the impact the exertion of respiratory measurements may have on the vascular assessments as well as our findings in previous particle exposure studies where vascular effects have been demonstrated at earlier time points than the respiratory effects [20]. Therefore, we cannot exclude a possible impact of ECA on pulmonary measurements during the initial $30 \mathrm{~min}$.

All study participants were young occasional smokers (maximum of ten cigarettes per month). Even though the cumulative cigarette exposure was quite low, we cannot fully exclude that smoking may have affected baseline values of our measurements.

\section{Conclusions}

This study systematically investigates the acute vascular and respiratory effects of e-cigarette aerosol, with and without added nicotine, in healthy volunteers, employing an array of well-validated, non-invasive methods. Our findings suggest that the increase in arterial stiffness and conducting airway obstruction seen following ECA inhalation is primarily caused by the added nicotine in ECA and may translate to clinical repercussions, particularly in susceptible populations as well as with chronic use.

Acknowledgements We would like to thank research nurses Annika Johansson and Frida Holmström and laboratory staff Dr. Jamshid Pourazar and Dr. Gregory Rankin as well as Ann-Britt Lundström at Umeå University for their technical support. We thank Prof. Anders Blomberg at Umeå University and Prof. Håkan Wallén at Karolinska Institutet Danderyd Hospital for their critical review of the manuscript. We would like to thank Jason Damewood for his technical assistance on the electronic cigarette device. This work was supported by the Swedish Heart and Lung Association, the Swedish Society of Medicine, the Swedish Heart-Lung Foundation and Stockholm County Council (ALF project). ML is supported by a clinical post-doctoral support from Karolinska Institutet and Stockholm County Council.

\section{Compliance with Ethical Standards}

Conflict of interest The authors declare that they have no competing interests.

Ethical Approval The study was approved by the local Ethics Review Board in Umeå. The study was performed in accordance to the Declaration of Helsinki and with the written informed consent of all participants.

Open Access This article is distributed under the terms of the Creative Commons Attribution 4.0 International License (http://creativecommons.org/licenses/by/4.0/), which permits unrestricted use, distribution, and reproduction in any medium, provided you give appropriate credit to the original author(s) and the source, provide a link to the Creative Commons license, and indicate if changes were made.

\section{References}

1. Lim, S. S., Vos, T., Flaxman, A. D., Danaei, G., Shibuya, K., Adair-Rohani, H., et al. (2012). A comparative risk assessment of burden of disease and injury attributable to 67 risk factors and risk factor clusters in 21 regions, 1990-2010: A systematic analysis for the Global Burden of Disease Study 2010. Lancet, 380(9859), 2224-2260. https://doi.org/10.1016/S0140-6736(12)61766-8.

2. WHO. (2015). WHO global report on trends in prevalence of tobacco smoking. Retrieved December 5, 2017, from http://www. who.int/tobacco/publications/surveillance/reportontrendstobacc osmoking/en/index4.html.

3. Schraufnagel, D. E., Blasi, F., Drummond, M. B., Lam, D. C., Latif, E., Rosen, M. J., et al. (2014). Electronic cigarettes. A position statement of the forum of international respiratory societies. American Journal of Respiratory and Critical Care Medicine, 190(6), 611-618. https://doi.org/10.1164/rccm.201407-1198pp.

4. Grana, R., Benowitz, N., \& Glantz, S. A. (2014). E-cigarettes: A scientific review. Circulation, 129(19), 1972-1986. https://doi. org/10.1161/CIRCULATIONAHA.114.007667.

5. Wieslander, G., Norback, D., \& Lindgren, T. (2001). Experimental exposure to propylene glycol mist in aviation emergency training: Acute ocular and respiratory effects. Occupational and Environmental Medicine, 58(10), 649-655. https://doi.org/10.1136/ oem.58.10.649.

6. Lorkiewicz, P., Riggs, D. W., Keith, R. J., Conklin, D. J., Xie, Z., Sutaria, S., et al. (2018). Comparison of urinary biomarkers of exposure in humans using electronic cigarettes, combustible cigarettes, and smokeless tobacco. Nicotine \& Tobacco Research. https://doi.org/10.1093/ntr/nty089.

7. Goniewicz, M. L., Gawron, M., Smith, D. M., Peng, M., Jacob, P., 3rd, \& Benowitz, N. L. (2017). Exposure to nicotine and selected toxicants in cigarette smokers who switched to electronic cigarettes: A longitudinal within-subjects observational study. Nicotine \& Tobacco Research, 19(2), 160-167. https://doi. org/10.1093/ntr/ntw160.

8. Carnevale, R., Sciarretta, S., Violi, F., Nocella, C., Loffredo, L., Perri, L., et al. (2016). Acute impact of tobacco versus electronic cigarette smoking on oxidative stress and vascular function. Chest, 150(3), 606-612. https://doi.org/10.1016/j.chest.2016.04.012.

9. Antoniewicz, L., Bosson, J. A., Kuhl, J., Abdel-Halim, S. M., Kiessling, A., Mobarrez, F., et al. (2016). Electronic cigarettes increase endothelial progenitor cells in the blood of healthy volunteers. Atherosclerosis, 255, 179-185. https://doi.org/10.1016/j. atherosclerosis.2016.09.064. 
10. Moheimani, R. S., Bhetraratana, M., Peters, K. M., Yang, B. K., Yin, F., Gornbein, J., et al. (2017). Sympathomimetic effects of acute e-cigarette use: Role of nicotine and non-nicotine constituents. Journal of the American Heart Association, 6(9), 2. https:// doi.org/10.1161/jaha.117.006579.

11. Chaumont, M., de Becker, B., Zaher, W., Culie, A., Deprez, G., Melot, C., et al. (2018). Differential effects of e-cigarette on microvascular endothelial function, arterial stiffness and oxidative stress: a randomized crossover trial. Scientific Reports, 8(1), 10378. https://doi.org/10.1038/s41598-018-28723-0.

12. Kerr, D. M. I., Brooksbank, K. J. M., Taylor, R. G., Pinel, K., Rios, F. J., Touyz, R. M., et al. (2019). Acute effects of electronic and tobacco cigarettes on vascular and respiratory function in healthy volunteers: A cross-over study. Journal of Hypertension, 37(1), 154-166. https://doi.org/10.1097/hjh.0000000000001890.

13. Lekakis, J., Abraham, P., Balbarini, A., Blann, A., Boulanger, C. M., Cockcroft, J., et al. (2011). Methods for evaluating endothelial function: A position statement from the European Society of Cardiology Working Group on Peripheral Circulation. European Journal of Cardiovascular Prevention and Rehabilitation, 18(6), 775-789. https://doi.org/10.1177/1741826711398179.

14. Vardavas, C. I., Anagnostopoulos, N., Kougias, M., Evangelopoulou, V., Connolly, G. N., \& Behrakis, P. K. (2012). Shortterm pulmonary effects of using an electronic cigarette: Impact on respiratory flow resistance, impedance, and exhaled nitric oxide. Chest, 141(6), 1400-1406. https://doi.org/10.1378/chest.11-2443.

15. Oostveen, E., MacLeod, D., Lorino, H., Farre, R., Hantos, Z., Desager, K., et al. (2003). The forced oscillation technique in clinical practice: Methodology, recommendations and future developments. European Respiratory Journal, 22(6), 1026-1041. https ://doi.org/10.1183/09031936.03.00089403.

16. Schober, W., Szendrei, K., Matzen, W., Osiander-Fuchs, H., Heitmann, D., Schettgen, T., et al. (2014). Use of electronic cigarettes (e-cigarettes) impairs indoor air quality and increases FeNO levels of e-cigarette consumers. International Journal of Hygiene and Environmental Health, 217(6), 628-637. https://doi.org/10.1016/j. ijheh.2013.11.003.

17. Flouris, A. D., Chorti, M. S., Poulianiti, K. P., Jamurtas, A. Z., Kostikas, K., Tzatzarakis, M. N., et al. (2013). Acute impact of active and passive electronic cigarette smoking on serum cotinine and lung function. Inhalation Toxicology, 25(2), 91-101. https:// doi.org/10.3109/08958378.2012.758197.

18. Hirata, K., Kawakami, M., \& O’Rourke, M. F. (2006). Pulse wave analysis and pulse wave velocity: A review of blood pressure interpretation 100 years after Korotkov. Circulation Journal, $70(10), 1231-1239$.

19. Miller, M. R., Hankinson, J., Brusasco, V., Burgos, F., Casaburi, R., Coates, A., et al. (2005). Standardisation of spirometry. European Respiratory Journal, 26(2), 319-338. https://doi. org/10.1183/09031936.05.00034805.

20. Lundback, M., Mills, N. L., Lucking, A., Barath, S., Donaldson, K., Newby, D. E., et al. (2009). Experimental exposure to diesel exhaust increases arterial stiffness in man. Particle and Fibre Toxicology, 6, 7. https://doi.org/10.1186/1743-8977-6-7.

21. Mitchell, G. F., Hwang, S. J., Vasan, R. S., Larson, M. G., Pencina, M. J., Hamburg, N. M., et al. (2010). Arterial stiffness and cardiovascular events: The Framingham heart study. Circulation, 121(4), 505-511. https://doi.org/10.1161/CIRCULATIO NAHA.109.886655.

22. Franzen, K. F., Willig, J., Cayo Talavera, S., Meusel, M., Sayk, F., Reppel, M., et al. (2018). E-cigarettes and cigarettes worsen peripheral and central hemodynamics as well as arterial stiffness: A randomized, double-blinded pilot study. Vascular Medicine, 23(5), 419-425. https://doi.org/10.1177/1358863×18779694.
23. Lee, J., \& Cooke, J. P. (2011). The role of nicotine in the pathogenesis of atherosclerosis. Atherosclerosis, 215(2), 281-283. https ://doi.org/10.1016/j.atherosclerosis.2011.01.003.

24. Stepanov, I., Jensen, J., Hatsukami, D., \& Hecht, S. S. (2008). New and traditional smokeless tobacco: Comparison of toxicant and carcinogen levels. Nicotine \& Tobacco Research, 10(12), 1773-1782. https://doi.org/10.1080/14622200802443544.

25. Arefalk, G., Hambraeus, K., Lind, L., Michaelsson, K., Lindahl, B., \& Sundstrom, J. (2014). Discontinuation of smokeless tobacco and mortality risk after myocardial infarction. Circulation, 130(4), 325-332. https://doi.org/10.1161/CIRCULATIO NAHA.113.007252.

26. Hansson, J., Galanti, M. R., Hergens, M. P., Fredlund, P., Ahlbom, A., Alfredsson, L., et al. (2012). Use of snus and acute myocardial infarction: Pooled analysis of eight prospective observational studies. European Journal of Epidemiology, 27(10), 771-779. https:// doi.org/10.1007/s10654-012-9704-8.

27. Hansson, J., Galanti, M. R., Hergens, M. P., Fredlund, P., Ahlbom, A., Alfredsson, L., et al. (2014). Snus (Swedish smokeless tobacco) use and risk of stroke: Pooled analyses of incidence and survival. Journal of Internal Medicine, 276(1), 87-95. https://doi. org/10.1111/joim.12219.

28. Carlsson, S., Andersson, T., Araghi, M., Galanti, R., Lager, A., Lundberg, M., et al. (2017). Smokeless tobacco (snus) is associated with an increased risk of type 2 diabetes: Results from five pooled cohorts. Journal of Internal Medicine, 281(4), 398-406. https://doi.org/10.1111/joim.12592.

29. Joseph, A. M., Norman, S. M., Ferry, L. H., Prochazka, A. V., Westman, E. C., Steele, B. G., et al. (1996). The safety of transdermal nicotine as an aid to smoking cessation in patients with cardiac disease. The New England Journal of Medicine, 335(24), 1792-1798. https://doi.org/10.1056/nejm199612123352402.

30. Benowitz, N. L., Porchet, H., Sheiner, L., \& Jacob, P., 3rd. (1988). Nicotine absorption and cardiovascular effects with smokeless tobacco use: Comparison with cigarettes and nicotine gum. Clinical Pharmacology and Therapeutics, 44(1), 23-28.

31. Lunell, E., \& Curvall, M. (2011). Nicotine delivery and subjective effects of Swedish portion snus compared with $4 \mathrm{mg}$ nicotine polacrilex chewing gum. Nicotine \& Tobacco Research, 13(7), 573-578. https://doi.org/10.1093/ntr/ntr044.

32. Wagener, T. L., Floyd, E. L., Stepanov, I., Driskill, L. M., Frank, S. G., Meier, E., et al. (2017). Have combustible cigarettes met their match? The nicotine delivery profiles and harmful constituent exposures of second-generation and third-generation electronic cigarette users. Tobacco Control, 26(e1), e23-e28. https:// doi.org/10.1136/tobaccocontrol-2016-053041.

33. Hansson, L., Choudry, N. B., Karlsson, J. A., \& Fuller, R. W. (1994). Inhaled nicotine in humans: Effect on the respiratory and cardiovascular systems. Journal of Applied Physiology, 76(6), 2420-2427.

34. Garcia-Arcos, I., Geraghty, P., Baumlin, N., Campos, M., Dabo, A. J., Jundi, B., et al. (2016). Chronic electronic cigarette exposure in mice induces features of COPD in a nicotine-dependent manner. Thorax, 71(12), 1119-1129. https://doi.org/10.1136/thora xjnl-2015-208039.

35. Chaudhuri, R., Livingston, E., McMahon, A. D., Lafferty, J., Fraser, I., Spears, M., et al. (2006). Effects of smoking cessation on lung function and airway inflammation in smokers with asthma. American Journal of Respiratory and Critical Care Medicine, 174(2), 127-133. https://doi.org/10.1164/rccm.20051 0-15890C.

36. Polosa, R., Morjaria, J., Caponnetto, P., Caruso, M., Strano, S., Battaglia, E., et al. (2014). Effect of smoking abstinence and reduction in asthmatic smokers switching to electronic cigarettes: Evidence for harm reversal. International Journal of 
Environmental Research and Public Health, 11(5), 4965-4977. https://doi.org/10.3390/ijerph110504965.

37. Cho, J. H., \& Paik, S. Y. (2016). Association between electronic cigarette use and asthma among high school students in South Korea. PLoS ONE, 11(3), e0151022. https://doi.org/10.1371/journ al.pone. 0151022 .
Publisher's Note Springer Nature remains neutral with regard to jurisdictional claims in published maps and institutional affiliations. 